\title{
Evaluation of Different Control Methods Against Citrus Rind Borer (Prays endolemma Diakonoff)
}

Larry V. Aceres', Marjun A. Mamangun, Emelie G. Pelicano, Jerald Anthony P. Esteban and Jesryl L. Paulite

\begin{abstract}
The Citrus rind borer also known as citrus pock caterpillar is still the most critical pest-infesting pummelo (Citrus maxima Merr.) in the Philippines particularly in Davao region. Management of the pest is indispensable for successful pummelo production. The study was conducted to determine the best cost-effective treatment to manage the pest-infesting pummelo. The experiment was laid out in Completely Randomized Design (CRD) with five treatments replicated three times. The treatments were: curry tree leaf leachate, neem tree leaf leachate, bagging with an ordinary net, treated check (Chlorpyrifos + Beta-cyfluthrin), and untreated check. Data were analyzed using Analysis of Variance while the differences among treatment means were computed using the Tukey's Honest Significant Difference. Results revealed that the cost-effective treatment against
\end{abstract}

$1 \quad$ The lead author, a faculty of the College of Agriculture and Related Sciences, would like to thank the Commission on Higher Education (CHED) and the University of Southeastern Philippines for funding this research as well as the students namely Marjun Mamangun, Edbert Casera, Emmanuel Libuangan, John Henry Millena and Niel Rhey Encierto for providing support especially in the application of treatments and data collection.

Contact the lead author at larry.aceres@usep.edu.ph. 
the destructive citrus rind borer is the bagging treatment. Bagging of fruits is more economical and environmentally sound over the use of chemical pesticides (Chlorpyrifos + Beta-cyfluthrin).

Keywords: curry tree (Murraya koenigii), neem tree (Azadirachta indica), bagging, citrus rind borer, sustainable pest management

Pummelo (Citrus maxima Merr.), the largest citrus fruit, is classified as a high-value cash crop and extensively grown in the Philippines because it is widely adapted to local soil and climatic conditions. The significant challenges in pummelo production have been attributed to high incidence of insect pests and diseases, high cost of agrochemicals, improper nutritional management, poor post-harvest handling, and limited availability of disease-free planting materials (Lasquites et al. 2011).

Citrus rind borer (Prays endolemma Diakonoff) is one of the most important insect pests of citrus in the Philippines. Damages to pummelo alone could reach as high as 60-80 percent (Gavarra and Costales, 1989). The larva feeds on the rind of various citrus fruits, causing galllike swellings (pocks). Larval development is completed within these galls and the larva never enters the endocarp. It completes its life cycle in either flowers or fruits of pummelos, oranges, calamansi, and other citrus cultivars. Infestation in the early stages of fruit development will lead to malformation of pummelo fruits (Pableo and Araño, 2009). 
The neem tree (Azadirachta indica) is a tropical evergreen tree native to India and also found in Southeast Asian countries. The scientific community has proven its pesticidal and medicinal importance. The World Health Organization also identified the tree as an environmentally powerful natural pesticide. The tree is considered to be one of the most promising trees of the 21 st century for its great potential in pest management, environment protection and medicine (Nicoletti et al., 2012).

On the other hand, Murraya koenigii, commonly known as curry leaf tree, is a small deciduous-to-semi-evergreen tree found throughout India. It has been used as a spice for its aroma and as an herb in Ayurvedic medicine. There are a few reports about the pesticidal effect of $M$. koenigii against some insect pests (Senrung et al., 2014). Because of the characteristic scent of the tree that can be compared to the pesticide Malathion, an organophosphate insecticide, organic farmers named it as "malathion tree" in the Philippines. Several growers of pummelo and durian in the Philippines revealed the efficacy of the botanical extracts against major pests of the mentioned crops particularly against the citrus rind borer (Aceres, 2012). Hence, in this study, the curry leaf tree and the neem tree were evaluated for their efficacy against citrus rind borerinfesting pummelo in Mabini, Compostela Valley, Philippines.

Moreover, Pableo and Simpao (2009) reported that the use of bagging materials made from synthetic net is effective in managing citrus rind borer in pummelo orchard. Sharma et al (2014) further revealed that pre-harvest fruit bagging is indispensable in providing physical barrier against insect pests, diseases and bird pests; reduces agrochemical residues on fruits; promotes skin coloration and reduces blemishes on fruits; and, improves internal fruit quality. In Japan, USA, Australia and China, the use of fruit bagging is an integral component of crop production among high valued crops such as pear, apple, grapes 
and peach. Thus, this technique was validated against the citrus rind borer in pummelo, as discussed in this paper. The study was interested in determining the best cost-effective treatment to manage the citrus rind borer in pummelo.

\section{Materials and Methods}

\section{Site and duration of the study}

The study was conducted at the pummelo orchard of the University of Southeastern Philippines, Tagum-Mabini Campus, Pindasan, Mabini, Compostela Valley Province, Philippines from April 2014 to October 2014.

\section{Experimental design and treatments}

The study was laid out using a Completely Randomized Design (CRD) with five treatments replicated three times. When the significant analysis was obtained from the Analysis of Variance, the Tukey's Honest Significant Difference was used to separate significant mean differences. The treatments were as follows:

$\mathrm{Tl}$ - Curry tree leaves leachate applied from flowering and every four days up to two months.

T2 - Neem tree leaves leachate applied from flowering and every four days up to two months.

T3 - Bagging of flowers/fruits using an ordinary plastic net bag from flowering up to two months.

T4 - Treated check (Chlorpyrifos + Beta-cyfluthrin) applied from flowering and every four days up to two months.

T5 - Untreated check (no application of treatments) 


\section{Treatment collection and preparation}

The neem tree leaves were collected from Tagnanan, Mabini, Compostela Valley Province while the curry tree leaf was taken from the Lara Farm, San Vicente, Asuncion, Davao del Norte. These botanical treatments were cleaned using running tap water to remove dirt. Using a sharp bolo/knife, the botanicals were chopped to about one $\mathrm{cm}$ long and were placed inside a net bag synonymous to a tea bag. It was then placed in a clean container added with 20 liters of clean water. The leachates after 48 hours were taken after filtering with a clean cloth for direct application to pummelo flowers/fruits. Five grams of detergent powder was then added to serve as a surfactant to the botanicals per 16 liters of the solution (leachate). The net bag as bagging material was purchased in a public market in Tagum City. The chemical check (Chlorpyrifos + Beta-cyfluthrin) was purchased from an accredited agricultural supplier from same city. This insecticide was used because it is the most effective product against citrus rind borer (CRB) of pummelo based on Evangelista et al. (2005).

\section{Experimental trees and treatment application}

Fifteen (15) pummelo trees that flower simultaneously were used in the study. For each tree, fifteen (15) sample flowers and/or fruits per treatment per replication was used. Tagging of samples was done with great care.

Treatment application was made using a knapsack sprayer. One knapsack sprayer was used for one treatment and so with the other treatments. Application of treatments commences from the time the pummelo trees bore a flower bud and every four days up to two months from flowering or a total of 15 treatment applications. Application of bagging materials commences as soon as the flower bud appears from pummelo trees. 


\section{Data Gathered}

Number of galls. The number of galls was recorded from 15 randomly selected fruits per treatment per replication. The assessment was done thrice - when the pummelo fruit reached marble size (approx. $20 \mathrm{~mm}$ ), five peso size (Philippine peso, approx. $27 \mathrm{~mm}$ ), and baseball size (approx. $73 \mathrm{~mm}$ ).

Percentage Severity Infestation (PSI). The percentage severity infestation was evaluated based on 15 sample fruits per treatment per replication, at marble, peso and baseball sizes. Percentage severity infestation (PSI) was determined following the damage rating scale from Evangelista et al. (2005) as given:

$\begin{array}{cc}\text { Rating } & \begin{array}{c}\text { Description } \\ \text { (\% of the fruit damage) }\end{array} \\ 0 & \text { No Damage } \\ 1 & 1-20 \\ 2 & 21-40 \\ 3 & 41-60 \\ 4 & 61-80 \\ 5 & 81-10\end{array}$

Based on the above rating scale, degree of infestation was computed using the formula:

$$
P S I=\frac{0(n)+1(n)+2(n)+3(n)+4(n)+5(n)}{5(N)}
$$

Efficacy of the treatments was based on the following scale:

$\begin{array}{ll}\text { PSI } & \text { DESCRIPTION } \\ 0-10 & \text { Very Effective } \\ 11-20 & \text { Moderately Effective } \\ 21-30 & \text { Less Effective } \\ 31 \text { and above } & \text { Not Effective }\end{array}$


Mean percent of marketable and non-marketable fruits. The marketable and non-marketable fruits were gathered based from 15 sample fruits per treatment and replication which were then converted to percent. Marketable fruits were further classified based on the Philippine National Standard for Pummelos (2004) but with slight modification using classifications class A and B. Class A pummelo fruits are those classified under Extra Class and Class 1 with good to superior quality and with very low to zero CRB infestation. Class B pummelo fruits refer to Class 2 with slight to moderate infestation caused by CRB but still can be marketed. Unmarketable fruits are those pummelos that cannot be marketed (or are impossible to market) due to heavy CRB infestation.

\section{Cost and return analysis}

Cost of production, net profit and return of investment were computed in determining which of the different organic inputs compared to chemically treated and untreated pummelo trees was the most economical. Cost of production was transformed on a per hectare basis.

\section{Results And Discussion}

\section{Number of galls and Percent Severity Infestation}

Mean number of galls and percent severity infestation produced by citrus rind borer in pummelo at different stages of fruit development in different treatments are presented in Tables 1 and 2.

Statistical analysis revealed significant differences among treatments. During the whole period of sampling, the curry tree leaf leachate and bagging treatments obtained the lowest number of galls, which is 
comparable to the treated check (Chlorpyrifos + Beta-cyfluthrin). On the other hand, pummelos treated with neem tree leaf leachate recorded the highest number of galls, which are comparable to the untreated check. The result is also similar in relation to the severity of infestation wherein the bagging and curry leaf leachate treatments are comparable to the treated check with significantly very low infestation. Neem treatment had high percent severity infestation comparable to the untreated check.

Results imply that the use of curry tree leaf leachate and bagging provided significant protection to pummelo fruits, which are comparable to the effects of the treated check (Chlorpyrifos + Betacyfluthrin).

Table 1. Mean number of galls in pummelo fruits at different stages of development as affected by different pest control strategies against citrus rind borer $^{1}$

\begin{tabular}{lccc}
\hline \hline \multicolumn{3}{c}{ COLLECTION PERIOD } \\
\hline \hline TREATMENTS & MARBLE STAGE** $^{*}$ & PESO STAGE** & BASEBALL STAGE $^{* *}$ \\
\hline \hline Curry tree leaf & $0.65^{\mathrm{a}}$ & $1.18^{\mathrm{a}}$ & $1.82^{\mathrm{a}}$ \\
\hline Neem tree leaf & $4.87^{\mathrm{ab}}$ & $9.11^{\mathrm{b}}$ & $12.20^{\mathrm{b}}$ \\
\hline Bagging & $0.11^{\mathrm{a}}$ & $0.27^{\mathrm{a}}$ & $0.35^{\mathrm{a}}$ \\
\hline Synthetic insecticide & $0.02^{\mathrm{a}}$ & $0.02^{\mathrm{a}}$ & $0.11^{\mathrm{a}}$ \\
\hline Control (untreated) & $10.91^{\mathrm{b}}$ & $12.04^{\mathrm{b}}$ & $15.51 \mathrm{~b}$ \\
\hline CV $(\%)=$ & 27.77 & 23.79 & 23.94 \\
\hline \hline
\end{tabular}

**Significant at $1 \%$ level

${ }^{1}$ means in a column with the same superscript are not significantly different from each other ANOVA, HSD based from 15 fruit samples per treatment and replication 
Table 2. Mean percent severity infestation in pummelo fruits at different stages of development as affected by different pest control strategies against citrus rind borer ${ }^{1}$

\begin{tabular}{lccc}
\hline \multicolumn{4}{c}{ COLLECTION PERIOD } \\
\hline TREATMENTS & MARBLE STAGE ${ }^{* *}$ & PESO STAGE & \\
\hline Curry tree leaf & $3.55^{\mathrm{a}}$ & $7.56^{\mathrm{a}}$ & $10.28^{\mathrm{a}}$ \\
\hline Neem tree leaf & $18.67^{\mathrm{ab}}$ & $26.67^{\mathrm{b}}$ & $32.89^{\mathrm{b}}$ \\
\hline \hline Bagging & $0.89^{\mathrm{a}}$ & $1.33^{\mathrm{a}}$ & $1.78^{\mathrm{a}}$ \\
\hline \hline Synthetic insecticide & $0.44^{\mathrm{a}}$ & $0.44^{\mathrm{a}}$ & $0.89^{\mathrm{a}}$ \\
\hline \hline Control (untreated) & $31.11^{\mathrm{b}}$ & $33.33^{\mathrm{b}}$ & $40.00^{\mathrm{b}}$ \\
\hline \hline CV $(\%)=$ & 27.31 & 20.56 & 22.60 \\
\hline
\end{tabular}

**Significant at $1 \%$ level

${ }^{1}$ means in a column with the same superscript are not significantly different from each other ANOVA, HSD based from 15 fruit samples per treatment and replication

\section{Mean percent of marketable and non-marketable fruits}

The mean percent marketable (Class A and B) and non-marketable pummelo fruits as affected by different pest management strategies against citrus rind borer are shown in Table 3.

Statistical analysis revealed significant differences among treatments. Pummelo fruits applied/bagged with a net bag and treated check (Chlorpyrifos + Beta-cyfluthrin) both obtained the highest percent marketable fruits (Class A) and lowest percent non-marketable pummelo fruits. This was followed by curry tree leaf leachate which obtained 55.55 percent (Class A) and 40 percent (Class B) marketable pummelo fruits and low non-marketable pummelo fruits - which are comparable to the net bag and treated check. The neem tree leaf leachate on the other hand had a result comparable to that of the untreated check - having low percent marketable fruits (Class A and B) and a high percent of nonmarketable fruits. 
The results indicate that curry tree leaf leachate, net bag and treated check (Chlorpyrifos + Beta-cyfluthrin) provide significant protection to the pummelo fruits. Neem tree leaf leachate is comparable to untreated checks which do not protect pummelo fruits from citrus rind borer infestation.

Table 3. Mean percent marketable (Class A and B) and non-marketable pummelo fruits as affected by different pest control strategies against citrus rind borer ${ }^{1}$

\begin{tabular}{llll}
\hline & MARKETABLE & & NON- MARKETABLE** \\
\hline TREATMENTS & CLASS A** $^{*}$ & CLASS B* & \\
\hline Curry tree leaf & $55.55^{\mathrm{b}}$ & $40.00^{\mathrm{a}}$ & $4.44^{\mathrm{a}}$ \\
\hline Neem tree leaf & $8.89^{\mathrm{c}}$ & $42.22^{\mathrm{a}}$ & $48.89^{\mathrm{b}}$ \\
\hline Bagging & $93.33^{\mathrm{a}}$ & $4.45^{\mathrm{b}}$ & $2.22^{\mathrm{a}}$ \\
\hline Synthetic insecticide & $95.56^{\mathrm{a}}$ & $4.44^{\mathrm{b}}$ & $0.00^{\mathrm{a}}$ \\
\hline Control (untreated) & $0.00^{\mathrm{c}}$ & $37.78^{\mathrm{a}}$ & $62.22^{\mathrm{b}}$ \\
\hline CV $(\%)=$ & 22.79 & 42.15 & 37.25 \\
\hline
\end{tabular}

$* *$ Significant at $1 \%$ level

1 means in a column with the same superscript are not significantly different from each other

ANOVA, HSD based from 15 fruit samples per treatment and replication

\section{Cost and return analysis}

Based on the cost and return analysis (see Table 4), pummelo fruits bagged with the net bag had the highest return of investment of 201.01\% with net income of PHP54,884.00. The next best treatment was the treated check (Chlorpyrifos + Beta-cyfluthrin) with a return of investment (ROI) of 193.29\% with net income of PHP55,078.00.

The result shows that the net bag is one of the effective alternative ways in controlling citrus rind borer; it is effective than using pesticides in pummelo fruits. Pableo and Araño (2009) have said that bagging of pummelo fruits prevents or minimizes the use of pesticides for the 
control of CRB infestation and enhances the production of good quality and pesticide-free fruits at a reduced cost.

Table 4. Cost and return analysis of the different treatments applied on pummelo trees against citrus rind $\operatorname{borer}^{1}(1 \mathrm{ha})$

\begin{tabular}{|l|c|c|c|c|c|}
\hline \multirow{2}{*}{ TREATMENTS } & \multicolumn{5}{|c|}{ TREATMENTS } \\
\cline { 2 - 6 } & T1 & T2 & T3 & T4 & T5 \\
\hline I. Variable Cost & & & & & \\
A. Labor & & & & & \\
& & & & & \\
1. Treatment & & & & & - \\
preparation (5x) & 2000.00 & 2000.00 & 1600.00 & - & - \\
2. Spraying (15x) & 6000.00 & 6000.00 & - & 6000.00 & 1200.00 \\
3. Weeding (3x) & 1200.00 & 1200.00 & 1200.00 & 1200.00 & 1200.00 \\
4. Harvesting (3x) & 1200.00 & 1200.00 & 1200.00 & 12400.00 \\
5. Fertilizing (6x) & 2400.00 & 2400.00 & 2400.00 & 2400.00 & 2400.00 \\
6. Pruning & 800.00 & 800.00 & 800.00 & 800.00 & 800 \\
& & & & & \\
B. Inputs & & & & & \\
1. Fertilizer & 11925.00 & 11925.00 & 11925.00 & 11925.00 & 11925.00 \\
2. Insecticide & - & - & - & 2800.00 & - \\
3. Organic inputs & 1125.00 & 1125.00 & - & - & - \\
4. Net Bag & - & - & 6000.00 & - & - \\
5. Herbicide & 2100.00 & 2100.00 & 2100.00 & 2100.00 & 2100.00 \\
6. Transportation & 1000.00 & 1000.00 & 70.00 & 70.00 & - \\
Total Variable Cost & 30150.00 & 29250.00 & 27295.00 & 28495.00 & 19625.00 \\
\hline II. Total Production & & & & & \\
Gross Income & 62334.00 & 23138.00 & 82179.00 & 83573.00 & 13733.00 \\
Net Income & 32184.00 & -6112.00 & 54884.00 & 55078.00 & -5892.00 \\
Return of Investment & $106.75 \%$ & $-20.90 \%$ & $201.01 \%$ & $193.29 \%$ & $-30.02 \%$ \\
& & & & & \\
\hline
\end{tabular}

\section{Legend:}

T1 - Curry tree leaves leachates

$\mathrm{T} 2$ - Neem tree leaves leachates

T3 - Bagging of flowers/fruits using an ordinary net bag

T4 - Treated Check (Chlorpyrifos + Beta-cyfluthrin)

T5 - Untreated Check

'based from one (1) hectare computation with 100 trees/ha at tree spacing of $10 \times 10 \mathrm{~m}$ PHP200.00 man/day@2 men

Farmgate pummelo price PHP35/kg (class A); PHP15/kg (class B)

Average number of fruit/tree $=35$ fruits (Based on the actual count of the experimental trees) Average weight $/$ fruit $=0.70 \mathrm{~kg} /$ fruit (Based on the actual weight of the experimental trees) 
Net bags are also recyclable therefore they can be used again in the succeeding production period of pummelo. Moreover, net bags were applied only once in the whole production period compared to treated check (Chlorpyrifos + Beta-cyfluthrin) which was applied many times by spraying. Lastly, net bags pose no health hazard and is environmentallyfriendly since it does not affect other beneficial insects inhabiting the orchard.

Furthermore, curry tree leaf leachate shows potential as an alternative method of controlling citrus rind borer infestation. As stated by Morton (1984), the Murraya koenigii is widely exploited today for the insect-repellent and insecticidal action of the leaves and extracts of the seeds. There is promise from the study as results showed that there is a return of investment of $106.75 \%$ with net income of PHP32,184.00 although somehow lower than the net income of treatment 3 (bagging) and treatment 4 (treated check [Chlorpyrifos + Beta-cyfluthrin]).

On the other hand, the neem tree leaf leachate obtained a negative ROI of -20.90\% with negative net income of -PHP6,112.00 showing its failure to protect pummelo fruits from citrus rind borer infestation. The untreated pummelo trees obtained a negative return of investment of $-30.02 \%$ with negative net income of -PHP5,892.00. The result implies that there is a continuous need to apply pest management treatments on pummelo fruits against citrus rind borer to obtain a reasonable profit in pummelo production. 


\section{Conclusion}

Curry tree leaf and bagging treatments provide significant protection to the pummelo fruits which are comparable to the treated check (Chlorpyrifos + Beta-cyfluthrin). On the other hand, neem tree leaf leachate is not effective in controlling citrus rind borer which is comparable to the untreated check. In cost and return analysis, the most economical treatment is the bagging treatment.

In conclusion, curry tree leaf and bagging treatments are as effective as the treated check (Chlorpyrifos + Beta-cyfluthrin) in controlling citrus rind borer infestation in pummelo, with the bagging treatment being the most economical.

The researcher recommends exploring further the efficacy of the curry tree leaf as it showed potential as botanical pesticide for the control of citrus rind borer of pummelo. 


\section{References}

Aceres, L. V. 2012. Population dynamics and management of rind borer in pummelo and its natural enemies. Southeastern Philippines Journal of Research and Development. 21(1): 97-108.

Evangelista, C. C., Tangonan, N. G. and Ruano, C. P. 2005. Development of integrated pest and disease management for citrus. USM CA Research Journal 13(2): 219-248.

Gavarra, M. R. and Costales, D.P. 1989. Monitoring and control of rind borer on pummelos. Bago Oshiro, Davao City: DA-XI/BPI.

Lasquites, J.J. S., Salibay, M.A.L., Lambojon, K. 2011. Optimum

Fertilization to Improve the Yield and Quality of Pummelo. Available from https:// cutt.ly/kwyl0QZ

Morton, J. F. 1984. The curry leaf tree (Murraya koenigii (L.) Sprengel) is attracting attention in Florida. Proceedings of the Florida State Horticultural Society. 97: 314-317.

Nicoletti, M., Maccioni, O., Coccioletti, T., Mariani, S. and Vitali, F. (2012). Neem Tree (Azadirachta indica A. Juss) as Source of Bioinsecticides, Insecticides - Advances in Integrated Pest Management, F. Perveen (Ed.), ISBN: 978-953-307-780- 2, InTech, Available from: http:// www.intechopen.com/books/insecticides-advances-in-integratedpest-management/neem- tree Azadirachta-indica-a-juss-as-sourceof-bioinsecticides

Pableo, F. B., and Arano, B. A. 2009. Citrus Rind Borer Control Management: A Leaflet of the Bureau of Plant Industry-Davao National Crop Research and Development Center, Bago Oshiro, Davao City. 
Pableo, F. B., and Simpao, J. T. 2009. The effect of different bagging materials of pummelo for the control of citrus rind borer and other insect pests. Paper presented during the celebration of DA-BAR anniversary. Available from: https://cutt.ly/1NWHle.

Bureau of Product Standards. 2004. Philippine National Standard: Fresh Fruits - Pummelo - Specification. of Trade and Industry. Pp 13. Available from: https://cutt.ly/hNEiLU.

Senrung, A., Singh, J., Sharma, S., Bhutia, T. N. and Singh, A.K. 2014. Effect of Murraya koenigii extracts on feeding and the ovipositional response of Spodoptera litura (Fab.) (Lepidoptera: Noctuidae). Available from: https://cutt.ly/9NWjrV

Sharma, R. R., Reddy, S. V. R. and Jhalegar, M. J. 2014. Pre-harvest fruit bagging: a useful approach for plant protection and improved post-harvest fruit quality - a review, The Journal of Horticultural Science and Biotechnology, 89:2, 101-113, DOI: 10.1080/14620316.2014.11513055 